\title{
Post Surgical Pain- The Transition from Acute to Chronic Pain
}

\author{
Michael JE Neil \& William A Macrae \\ Consultant Anaesthetists, \\ The Pain Service, Ninewells Hospital and Medical School, \\ Dundee, DD1 $9 S Y$
}

\section{S U M M A R Y P O I N T S}

- Chronic pain after surgery is common.

- Surgery is widely performed therefore the at risk population is large.

- The mechanisms of chronic pain after surgery are complex.

- There are many risk factors associated with onset of chronic post-surgical pain: demographic, genetic and medical.

- Unnecessary and inappropriate surgery should be avoided.

\section{Introduction}

It is only within the past 10 years that the general problem of chronic post-surgical pain (CPSP) has been recognised. Chronic pain had been identified as an outcome following many individual surgical procedures prior to this but little research was devoted to understanding the phenomenon. It was not until surgery was identified as being an aetiological factor in the development of chronic pain ${ }^{1}$ and a number of review articles on the subject were published ${ }^{2,3,4}$ that the scale of the problem became apparent.

Historically pain has been arbitrarily divided into acute and chronic with the belief that different mechanisms were involved in the development of each. Recent research however indicates that we should see the two as a continuum of the same underlying process. In the past ten years our understanding of how acute post-operative pain becomes chronic has increased with the elucidation of the physiological mechanisms underpinning central and peripheral nervous system processing of pain ${ }^{5}$, and the identification of risk factors, including demographic, psychosocial, genetic, and medical factors ${ }^{6,7}$.

The incidence of chronic pain after surgery varies markedly between studies and between operations, for example the incidence of chronic pain varies between $20-50 \%$ for mastectomy, 5-65\% for thoracotomy, $50-85 \%$ for amputation and $5-35 \%$ for herniorraphy. Due to the large numbers of patients undergoing these procedures each year and the subsequent impact of chronic pain on quality of life $^{8}$ and its economic consequences ${ }^{9}$ this is a major public health issue.

\section{Defining Chronic Post-Surgical Pain}

Defining when pain after surgery becomes chronic is difficult. Definitions stating that pain lasting longer than the usual period of healing or arbitrarily set time-scales of 3 or 6 months are frequently used. However, if a patient sustains nerve injury during an operation, they may have pain immediately after the operation which will be chronic. Surgery is frequently performed because of pain. If pain then persists post-operatively it can be difficult to establish if this is a continuation of the original problem or a new pain resulting from the operation.

A single operation may lead to a number of different pain syndromes. Thoracotomy is an example of this with post-operative pain potentially arising from the musculo-skeletal system from rib retraction, neuropathic pain from trauma to intercostal nerves, damage to internal organs producing visceral pain and pain arising from the placement of chest drains. Patients may present to Pain Clinics blaming surgery for their on-going pain but on questioning have had the same symptoms prior to the operation. If this original pain was neuropathic, surgery might aggravate the underlying problem.

In order to help standardise the definition, the following criteria have been suggested ${ }^{2}$

- The pain developed after a surgical procedure

- The pain is of at least two months duration

- Other causes for the pain have been excluded e.g. recurrent malignancy, chronic infection

- The possibility that the pain is continuing from a preexisting problem must be explored and exclusion attempted 
A standardised definition would help in allowing more comparable data to be collected from studies into post-surgical pain which until recently has been a major deficiency.

\section{Acute and Chronic Pain Physiology}

Many cases of chronic pain have their origins in an episode of acute pain. This is particularly true of chronic pain after surgery. Acute pain such as that from a surgical incision, initiates a series of neurochemical reactions at the site of injury, but also initiates a cascade of changes leading to sensitisation in the central nervous system. This hyperalgesic state probably represents an advantageous evolutionary mechanism, discouraging use of the injured part and allowing it to heal. Chronic pain after surgery may be in part a failure of the nervous system to return to its pre-injury settings.

A surgical stimulus leads to activation of nociceptors, high threshold neurones responsive to potentially injurious thermal, mechanical and chemical stimuli, and transmission of afferent signals via the spino-thalamic tract to the cerebral cortex. Nociceptive afferent signals can be amplified or attenuated at various points along this pathway. Peripherally, nociceptors can be sensitised by local release of various neurochemical factors that result in increased sensitivity to endogenous ligands and physical stimulation such that even innocuous stimuli may be experienced as pain. Sodium channel expression is also altered on injured or inflamed neurones which show an increased number and proportion of tetrodotoxin-resistant channels and the development of spontaneous ectopic activity.

Nociceptive afferent signals also initiate the process of central sensitisation. The dorsal horn of the spinal cord has been identified as a key area in this process. Nociceptive afferents synapse in superficial layers of the dorsal horn, laminae I and II, before projecting cranially. Nociceptive signals can be modified in the dorsal horn by a number of mechanisms of which Wide Dynamic Range (WDR) neurones and the $\mathrm{N}$-methyl-D-Aspartate (NMDA) receptor play a vital role. WDR neurones normally receive signals from innocuous as well as nociceptive sensory neurones from large areas of the body. However, with repeated nociceptive input the threshold of these WDR neurones can decrease and their receptive field widen. Underlying this process is NMDA receptor activation that leads to diverse intracellular changes that result in increased sensitivity of the WDR neurones. This is one mechanism responsible for the 'wind-up' phenomenon.

With both acute and chronic pain the changes seen in the nervous system are far reaching, not only affecting the nociceptors themselves but all components of the neural pathway up to and including the cortex. Cortical mapping studies have revealed changes occurring in the thalamus and cortex in chronic pain states. It is easy to see that with such a diffuse and complex pattern of change, one therapeutic strategy alone is unlikely to be effective in the treatment of chronic pain.

\section{Predicting who will develop chronic post-surgical pain}

The risk factors for developing chronic pain after surgery can be grouped into patient factors and medical factors. Patients will bring their genotype, past medical history, past experiences, beliefs and psychosocial circumstances. The environmental factors will then act on the patient including the type of surgery and anaesthetic, perioperative analgesia, and other treatments given.

Increasing age reduces the risk of chronic pain in breast surgery and hernia repair ${ }^{10,11,12}$. Whether other demographic factors, such as employment, housing and marital status are important is controversial ${ }^{11,12}$. Age and employment may affect levels of activity which could confound the issue.

Psychosocial factors can affect acute postoperative pain. In a review Munfano and Stevenson found a consistent relationship between preoperative anxiety and acute postoperative pain ${ }^{13}$. Other studies have shown that factors such as anxiety, extroversion, depression, catastrophising, educational level, previous chronic pain history and attitudes to medication can all influence outcome after surgery ${ }^{14,15,16,17}$. The results on the influence of psychosocial factors on chronic pain after surgery are contradictory ${ }^{18,19,20}$. Peters et $\mathrm{al}^{21}$ studied the somatic and psychological predictors of long term unfavourable outcomes after surgery. Duration of the operation (longer than three hours) and fear of surgery were associated with poor outcomes. Optimism did not affect chronic pain nor physical functioning but was associated with better recovery and higher quality of life. Catastrophising was not a risk factor for chronic pain.

Why some patients develop pain after an operation while others, after an identical operation and anaesthetic do not, is mysterious, but genetic factors are likely to be important. Animal work has shown that mice can be bred for susceptibility to neuropathic pain after injury and one of the genes responsible has been isolated ${ }^{22,23}$. Many clinicians working in the field have long suspected a link with certain other conditions which may act as genetic markers of susceptibility. These include fibromyalgia syndrome, migrainous headaches, irritable bowel syndrome and irritable bladder and Raynaud's syndrome (especially bipolar, with hot feet at night). Three recent studies of CPSP after hernia surgery and hysterectomy have provided some evidence to support this clinical observation ${ }^{24,25,26}$.

Pain prior to the operation has been found to be a risk factor for thoracotomy ${ }^{27}$ and pain following lower limb amputation ${ }^{28}$, but not for total hip replacement ${ }^{29}$. There is no doubt that severe acute post-operative pain is a risk factor for CPSP after a wide range of operations $\mathbf{s}^{29,30,31,32,33}$.

It is likely that pain around the time of the operation sensitises the nervous system ${ }^{34}$ and this sensitised state may be an important factor in the development of chronic pain. It seems sensible therefore to try to reduce the nociceptive input to the spinal cord during and after the operation. Anaesthetic techniques that achieve this should show a reduction in both postoperative pain and chronic pain. There are several papers that show benefit from regional anaesthesia for 
example after hysterectomy ${ }^{24}$ and Caesarean section ${ }^{33}$, but in practice it is hard to completely abolish pain after surgery ${ }^{35}$. Using a variety of different drugs around the time of surgery has been advocated, but the results remain controversial.

There is no simple correlation between the scale of the operation and CPSP. However Peters et $\mathrm{a}^{21}$ reported an increased incidence of chronic pain and poorer outcomes in general, in operations which lasted more than three hours. These patients will probably have had more serious pathology, other health issues affecting both the complexity of the operation and the outcome and complications, so these findings are not surprising. The type of surgery influences the incidence of CPSP, for example in a study of different types of breast surgery $^{36}$, the incidence of CPSP varied from $53 \%$ for mastectomy with reconstruction by implant, to $31 \%$ for mastectomy only, to $22 \%$ for breast reduction.

In the past there was debate about the influence of concomitant treatments, such as radiotherapy and chemotherapy on the risk of chronic pain. A recent study by Poleshuck et $\mathrm{al}^{32}$ found that radiotherapy, independent of other variables, increased the risk of chronic pain after surgery for breast cancer.

\section{Conclusion}

The transition from acute to chronic post-surgical pain is a complex multi-factorial problem. Acute post-operative and chronic pain share many similar clinical features and have their basis in the same underlying physiological changes. However, it is still not known why in some individuals these normal responses to injury do not subside with healing. CPSP should be seen as the inevitable consequence of surgery in a proportion of patients, like wound infection. It is not a sign that something has gone wrong and the surgeon is seldom to blame.

What is becoming increasingly clear is the importance of the role that more fundamental predispositions in a patient's genetic and psychological make-up have to play in the persistence of post-surgical pain. Future developments in genetic research will hopefully identify specific genes that increase a patient's susceptibility to pain. This, along with more targeted psychological approaches may give us a way forward in better management of this condition.

Although it is not possible to predict who will develop chronic pain after surgery, there are some strategies we can use to prevent or minimise the risks. First, we should strive to minimise unnecessary and inappropriate operations. Raised awareness amongst surgeons and clear information for patients about chronic pain after surgery may help dissuade patients from unnecessary operations. Secondly, great efforts must be made to provide effective post-operative pain relief for a long enough period to prevent sensitisation occurring. Finally, we must be aware of the problem and actively look for patients showing signs of neuropathic pain post-operatively. This would allow for early and aggressive intervention to minimise the chances of developing chronic pain.

\section{REFERENCES.}

1. Crombie IK, Davies HTO, Macrae WA. Cut and thrust: antecedent surgery and trauma among patients attending a chronic pain clinic. Pain 1998;76:167-171.

2. Macrae WA, Davies HTO. Chronic Postsurgical pain. In: Crombie IK, Linton S, Croft P, Von Korff M, LeResche L, editors. Epidemiology of pain. Seattle: International Association for the Study of Pain; 1999. p. 125-142.

3. Macrae WA. Chronic pain after surgery. British Journal of Anaesthesia 2001;87(1):88-98.

4. Perkins FM, Kehlet H. Chronic pain as an outcome of surgery. Anesthesiology 2000;93:1123-33.

5. Woolf CJ, Mannion RJ. Neuropathic pain: Aetiology, symptoms, mechanisms and management. Lancet 1999;353:1959-64.

6. Kehlet H, Jensen TS, Woolf C. Persistent postsurgical pain: risk factors and prevention. Lancet 2006;367:1618-25.

7. Macrae WA. Can we prevent chronic pain after surgery? In: Shorten G, Carr DB, Harmon D, Puig MM, Browne J, editors. Postoperative pain management. Philadelphia: Saunders Elsevier; 2006. p. 259-64.

8. Smith BH, Torrance N, Bennett MI, Lee AJ. Health and quality of life associated with chronic pain of predominantly neuropathic origin in the community. Clinical Journal of Pain 2007;23:143-9.

9. Blyth FM, March LM, Cousins MJ. Chronic pain-related disability and use of analgesia and health services in a Sydney community. Medical Journal of Australia 2003;179:84-87.

10. Tasmuth T, von Smitten K, Hietanen P, Kataja M, Kalso E. Pain and other symptoms after different treatment modalities of breast cancer. Ann Oncol 1995;6(5):453-9.

11. Smith WCS, Bourne D, Squair J, Phillips DO, Chambers WA. A retrospective cohort study of post mastectomy pain syndrome. Pain 1999;83:91-95.

12. Poobalan AS, Bruce J, King PM, Chambers WA, Krukowski $\mathrm{ZH}$, Smith WC. Chronic pain and quality of life following open inguinal hernia repair. Br J Surg 2001;88(8):1122-6.

13. Munafo MR, Stevenson J. Anxiety and surgical recovery. Reinterpreting the literature. J Psychosom Res 2001;51(4):58996.

14. Taenzer P, Melzack R, Jeans ME. Influence of psychological factors on postoperative pain, mood and analgesic requirements. Pain 1986;24(3):331-42. 
15. Katz J, Poleshuck EL, Andrus CH, Hogan LA, Jung BF, Kulick DI, et al. Risk factors for acute pain and its persistence following breast cancer surgery. Pain 2005;119(1-3):16-25.

16. Granot M, Ferber SG. The roles of pain catastrophizing and anxiety in the prediction of postoperative pain intensity: a prospective study. Clin J Pain 2005;21(5):439-45.

17. Pavlin DJ, Sullivan MJ, Freund PR, Roesen K. Catastrophizing: a risk factor for postsurgical pain. Clin J Pain 2005;21(1):83-90.

18. Katz J, Jackson M, Kavanagh BP, Sandler AN. Acute pain after thoracic surgery predicts long-term post-thoracotomy pain. The Clinical Journal of Pain 1996;12(1):50-5.

19. Tasmuth T, Estlanderb AM, Kalso E. Effect of present pain and mood on the memory of past postoperative pain in women treated surgically for breast cancer. Pain 1996;68(2-3):343-7.

20. Jess P, Jess T, Beck H, Bech P. Neuroticism in relation to recovery and persisting pain after laparoscopic cholecystectomy. Scand J Gastroenterol 1998;33(5):550-3.

21. Peters ML, Sommer M, de Rijke JM, Kessels F, Heineman E, Patijn J, et al. Somatic and psychologic predictors of long-term unfavorable outcome after surgical intervention. Ann Surg 2007;245(3):487-94.

22. Devor M, Raber P. Heritability of symptoms in an experimental model of neuropathic pain. Pain 1990;42(1):51-67.

23. Seltzer Z, Wu T, Max MB, Diehl SR. Mapping a gene for neuropathic pain-related behaviour following peripheral neurectomy in the mouse. Pain 2001;93(2):101-6.

24. Brandsborg B, Nikolajsen L, Hansen CT, Kehlet H, Jensen TS. Risk factors for chronic pain after hysterectomy: a nationwide questionnaire and database study. Anesthesiology 2007;106(5):1003-12.

25. Courtney CA, Duffy K, Serpell MG, O’Dwyer PJ. Outcome of patients with severe chronic pain following repair of groin hernia. Br J Surg 2002;89(10):1310-4.

26. Wright D, Paterson C, Scott N, Hair A, O’Dwyer PJ. Fiveyear follow-up of patients undergoing laparoscopic or open groin hernia repair: a randomized controlled trial. Ann Surg 2002;235(3):333-7.

27. Keller SM, Carp NZ, Levy MN, Rosen SM. Chronic post thoracotomy pain. The Journal of Cardiovascular Surgery 1994;35(Suppl. 1 to No. 6):161-4.

28. Nikolajsen L, Ilkjaer S, Kroner K, Christensen JH, Jensen TS. The influence of preamputation pain on postamputation stump and phantom pain. Pain 1997;72:393-405.
29. Nikolajsen L, Brandsborg B, Lucht U, Jensen TS, Kehlet H. Chronic pain following total hip arthroplasty: a nationwide questionnaire study. Acta Anaesthesiol Scand 2006;50(4):495500 .

30. Kalso E, Perttunen K, Kaasinen S. Pain after thoracic surgery. Acta Anaesthesiol Scand 1992;36:96-100.

31. Aasvang E, Kehlet H. Chronic postoperative pain: the case of inguinal herniorrhaphy. Br J Anaesth 2005;95(1):69-76.

32. Poleshuck EL, Katz J, Andrus CH, Hogan LA, Jung BF, Kulick DI, et al. Risk factors for chronic pain following breast cancer surgery: a prospective study. J Pain 2006;7(9):626-34.

33. Nikolajsen L, Sorensen HC, Jensen TS, Kehlet H. Chronic pain following Caesarean section. Acta Anaesthesiol Scand 2004; $48(1): 111-6$.

34. Woolf CJ, Salter MW. Neuronal plasticity: increasing the gain in pain. Science 2000;288(5472):1765-9.

35. McLeod G, Davies H, Munnoch N, Bannister J, MacRae W. Postoperative pain relief using thoracic epidural analgesia: outstanding success and disappointing failures. Anaesthesia 2001;56(1):75-81.

36. Wallace MS, Wallace AM, Lee J, Dobke MK. Pain after breast surgery: a survey of 282 women. Pain 1996;66(2-3):195-205. 